Faculdade de Ciências Econômicas UFRGS
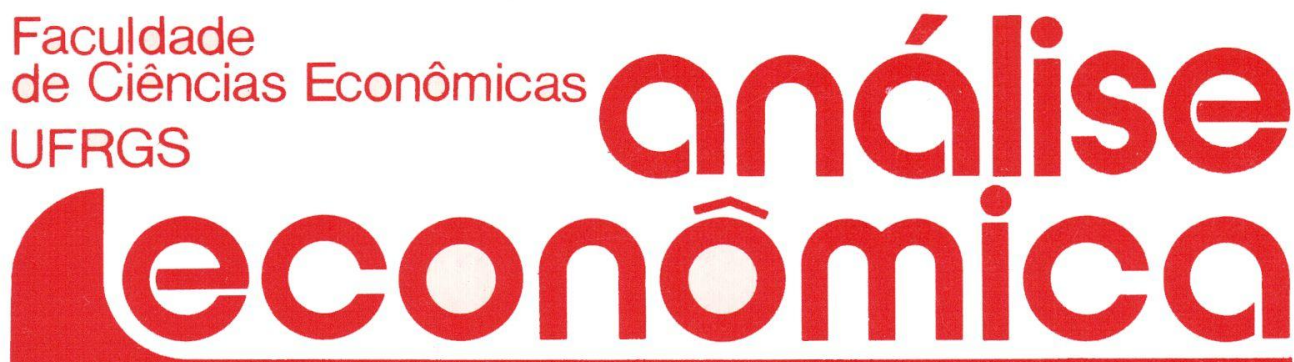

nesta edição:

- POLIITICA SALARIAL:

Roberto Camps Moraes

- DIVIDA EXTERNA:

Yeda Rorato Crusius

-- MECANISMO DAS

RETIFICACCÖES ORÇAMENTÁRIAS:

Manoel Marques Leite

- CREDITO RURAL: Zung Che Yee

- INDL'STRIA E CRISE ATUAL: Claudio F. Accurso
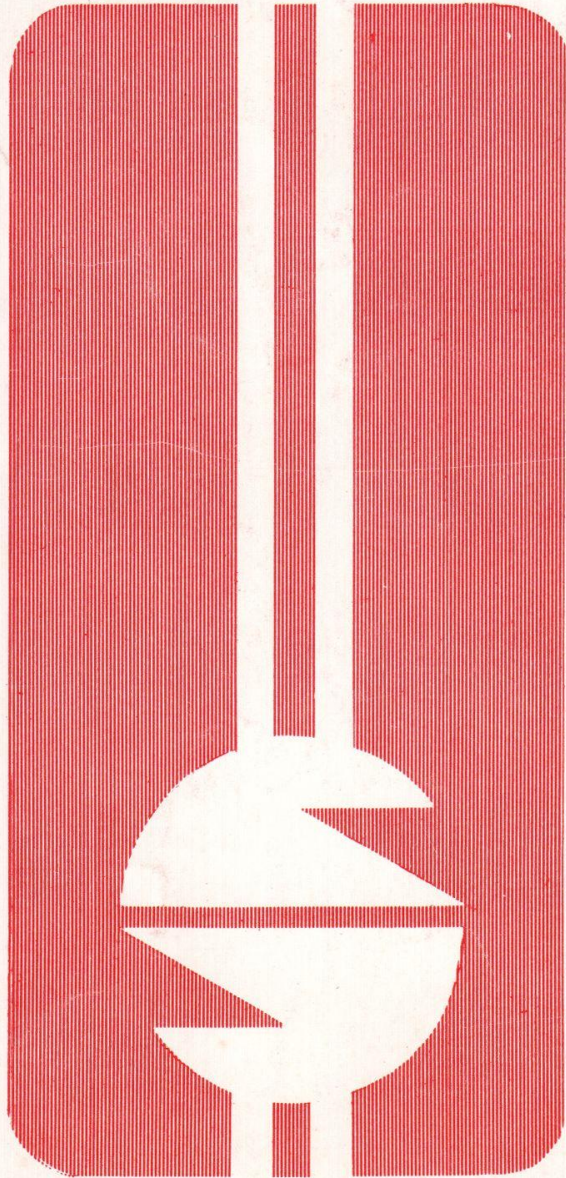

anv 1 
DIRETOR DA FACULDADE DE CIÊNCIAS ECONÓMICAS:

Prof. Antônio Carlos Santos Rosa

VICE-DIRETOR: Prof. Nelson Rokembach

CHEFE DO DEPARTAMENTO DE CIÉNCIAS ECONÔMICAS:

Prof. Renato Batista Masina

CONSELHO EDITORIAL: Prof. Pedro Cezar Dutra Fonseca (Presidente)

Prof. Achyles Barcelos da Costa

Prof. Carlos Augusto Crusius

Prof. Claudio Francisco Accurso

Prof. Edgar Augusto Lanzer

Prof. Ernani Hickmann

Prof. Nali de Jesus de Souza

Prof. Nuno Renan L. de Figueiredo Pinto

Profa Otilia Beatriz Kroeff Carrion

Prof. Roberto Camps Moraes

Profa Yeda Rorato Crusius

ANÁLISE ECONÓMICA é uma publicação semestral da Faculdade de Ciências Econômicas da Universidade Federal do Rio Grande do Sul, visando divulgar estudos e pesquisas de seu corpo docente e discente na área de Economia. Aceitam-se, entretanto, artigos e resenhas bibliográficas de economistas e técnicos não vinculados à Instituição. As matérias assinadas são de responsabilidade exclusiva dos autores. E permitida a reprodução: parcial para fins didáticos.

Toda a correspondência, material para publicação, assinaturas e permutas devem ser dị̣igidas a:

Prof. PEDRO CEZAR DUTRA FONSECA

Revista Análise Econômica

Avenida João Pessoa, $52-3$ ? andar

90.000 - Porto Alegre (RS) - Brasil

Esta edição é uma cortesia do grupo

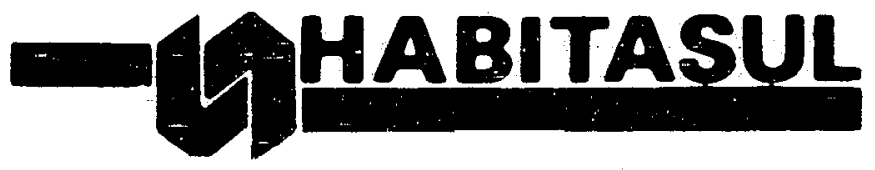




\section{A NOVA POLITTICA SALARIAL: ALGUNS EFEITOS ESPERADOS E OBSERVADOS *}

Roberto Camps Moraes **

\section{INTRODUÇĀO}

O presente trabalho busca analisar os efeitos esperados e os primeiros resultados já observados da introdução da nova política salarial. Deve-se entender por "nova política salarial" a nova sistemática de reajustes implantada pela Lei n. 6.708 , de 30/10/79, com as posteriores modificações introduzidas no final de $1980^{1}$. Desta nova sistemática de reajustes, consideramos que há dois aspectos novos e importantes que configuram uma mudança significativa nos objetivos implícitos da pol ítica salarial. O primeiro relaciona-se com a mudança na periodicidade do reajuste - passando de anual para semestral - e o segundo com a introdução de reajustes diferentes de acordo com a faixa de salário. Julgamos que esses dois aspectos comportam, do ponto de vista teórico, efeitos esperados diferentes. Por este motivo, achamos conveniente aividir o presente trabalho em três partes distintas. Na parte 2, apresentamos os efeitos esperados de uma mudança na periodicidade dos reajustes ignorando as diferenciações dos mesmos. Na parte 3, apresentamos os efeitos esperados e os resultados encontrados provenientes da existência da diferenciação nos reajustes. Finalmente, na parte 4 , apresentamos algumas considerações finais relacionadas com a discussão desenvolvida nas partes anteriores.

* Este trabalho é o produto do esforço de sistematizaça - empreendido pelo autor - dos resultados nas pesquisas efetuadas sobre os possiveis efeitos da nova política salarial, quando foi chamado a participar do Seminário sobre Atualidade Económica, promovido pela Faculdade de Ciências Económicas da UFRGS conjuntamente com a Sociedade de Economia do RGS, no periodo 1/6. $7 / 6,1982$.

* Do Centro de Estudos e Pesquisas Económicas (IEPE) e do Departamento de Ciências Económicas da UFRGS.

1 Para uma descriçáo completa dos princípios e dos detalhes da nova política salarial, consultar Carvalho (1982), Macedo (1981), ou Camargo (1980). 


\section{OS EFEITOS DA MUDANC̣A NA PERIODICIDADE}

Para analisarmos o que ocorre quando passamos de um regime de reajustes anuais de salário para um de reajustes semestrais, necessitamos, preliminarmente, definir alguns pontos. "Reajuste", por exemplo, será aqui definido como a reposição integral do pico anterior de salário real vigente no instante zero do período considerado. Este reajuste será considerado uniforme nesta parte, tal como já o indicamos na introdução. Por outro lado, qual quer variação na taxa de inflação al tera necessariamente a trajetória temporal do salário real em um período considerado. Por este motivo, para que comparemos ambos os regimes de reajustes salariais, é conveniente que o façamos sob a hipótese de uma taxa instantânea de inflação constante. Nestas circunstâncias, a figura $I$ indica a trajetória temporal do salário real, $\frac{w}{p}$, para uma dada taxa de inflação sob os dois regimes alternativos. Quanto ${ }_{\text {temos }}$

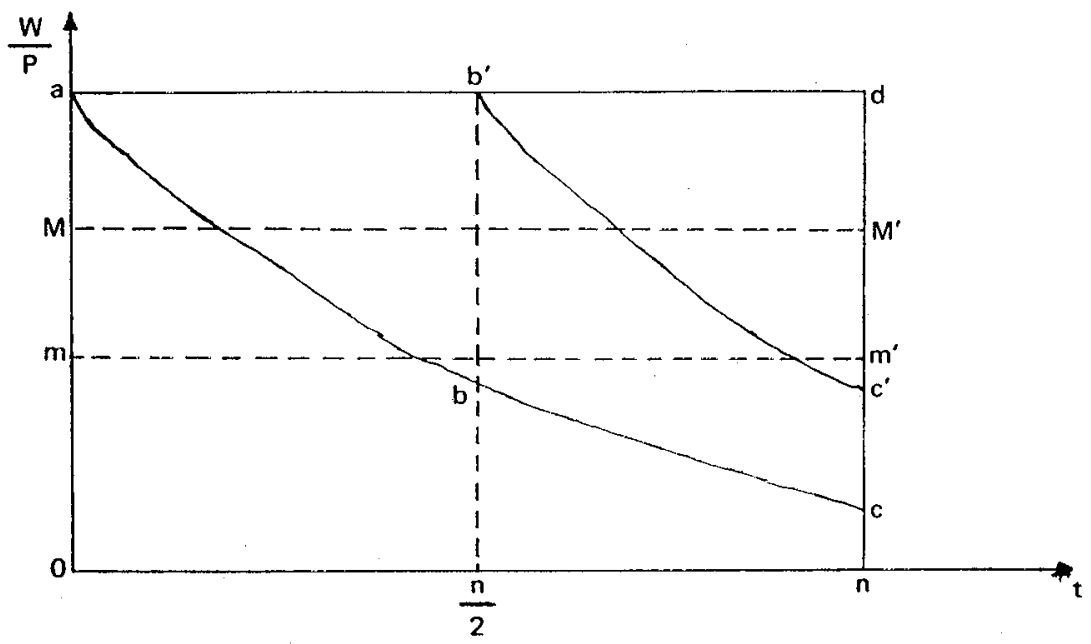

\section{FIGURA I}

o regime anual de reajuste de salários, a trajetória temporal real mensal que vigora é a descrita pela linha a b c, consistente de um salário mensal médio real dado pela áitura om. A perda total de salário real devida puramente à existência de uma taxa positiva de inflação é dada pela área a $\mathrm{d} \mathrm{c}$ - formada pela diferença entre o que o assalariado receberia se vigorasse a estabilidade de preço (área do retângulo o a d $n$ ) e o que ele recebe efetivamente (área do trapézio oacn). Uma medida da perda relativa do salário real durante o ano (extensão on do perf́odo) devido puramente à existência de uina taxa positi- 
va e constante de inflação é, portanto, o quociente da área acd pela área oadn $^{2}$.

Por outro lado, quando temos o regime de reajuste semestral de salários, a trajetória temporal do salário real mensal que vigora é a descrita pela linha $a b b^{\prime} c^{\prime}$-... com uma descontinuidade em $b^{\prime}$ - a qual é consistente com um salário médio real dado pela altura OM. A perda total de salário, tal como definida acima, é agora formada pela soma das áreas abb' e b'c'd a qual é menor do que a perda total do regime anual por uma diferença igual à área bb'cc'. Este "ganho" de salário real, decorrente da passagem de um regime de reajuste anual para um de reajuste semestral, materializa-se em toda a extensão indicada pela área bb'cc' se e somente se a taxa de inflação permanecer exatamente a mesma, antes, durante e depois da transição de um regime a outro. Na verdade, se usarmos o conceito acima esboçado de perda relativa de salário (PRS) devida puramente à inflação ${ }^{3}$ verificaremos que esta perda, para um dado regime de reajuste, é uma função crescente da tax $\exists$ de inflação. Se mudamos $₫$ regime de reajuste, de tal forma que o novo regime possua períodos mais curtos - como é o caso da passagem do anual para o semestral - a função PRS desloca-se para baixo no plano PRS - $r$ (onde $r$ é a taxa de inflação). Ou seja, para uma dada taxa de inflação, a PRS correspondente ao novo regime é menor, tal como indica a figura II: para a taxa de inflação $r_{0}$, a PRS no regime "antigo" é oa, ao passo que no "novo" regime ela é oa'. Esta trajetória que vai do ponto $A$ para o ponto $A$ ' corresponde ao caso em que a cláusula "coeteris paribus" aplica-se rigorosamente

o caso representado pelo "ganho" medido pela área bb'cc da figura I. Se, no entanto, introduzirmos um pouco de teoria e evidência empírica sobre a

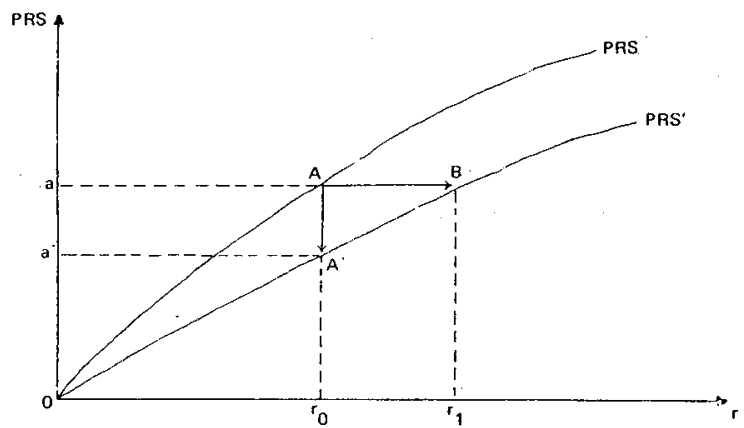

FIGURA II

2 Fste procedimento é o que adotamos em Moraes (1982.a) para a formulação de um método de mensuração das perdas de salário e dos ganhos de lucros derivados da inflação.

3 Para maiores detalhes sobre a metodologia implícita, consultar iiloraes (1982.a). 
formação de preços em uma economia semi-industrial oligopólica ${ }^{4}$, imediatamente constataremos que a cláusula "coeteris paribus" não pode ser rigorosamente mantida. Pelo contrário, é de se esperar que as firmas repassem via aumentos de preços os aumentos de custos gerados pela mudança no regime de reajustes, preservando suas margens de lucro. Se elas forem perfeitamente bem sucedidas nesta tentativa, a economia deslocar-se-á do ponto A para o ponto B na figura $11^{5}$. Neste caso, a PRS mantem-se constante durante o período total de 12 meses, o que, em termos da figura I, poderia ser representado por um deslocamento para baixo da trajetória abb'c', devido à aceleração da inflação para $r_{1}$, tal que o salário médio real permanecesse igual a om. O resultado, nesta hipótese, seria apenas um aumento na taxa de inflação que restituiria os valores reais anteriores do salário e das margens de lucro ${ }^{6}$. Obviamente, qualquer outro resultado é possível: uma taxa de inflação dentro do intervalo $r_{0}<r<r_{1}$ gera um aumento real no salário médio, embora menor do que o dado pela área $b^{\prime} b^{\prime} c^{\prime}$ da figura I. Tamikśm é verdade, no entanto, que se a taxa de inflação sofrer uma aceleração maior, situando-se em um patamar acima de $r_{1}$, o salário médio real cairá sob o novo regime de reajustes.

Até aqui examinamos as possibilidades decorrentes da mudança na periodicidade do reajuste no que se refere ao salário real e às margens de lucro. Mas também é importante saber o que se pode esperar teoricamente em relação ao comportamento dos níveis de produção e emprego. Fodemos estudar estes sob duas hipóteses extremas. Se a taxa de inflação permanece constante - trajetória $\mathrm{AA}^{\prime}$ da Figura II - o salário médio real do ano sofre uma elevação que é aproximadamente igual a $50 \%$ no caso da passagem do regime anual para o semestral. Sob esta hipótese extrema - que supõe, por sinal, concorrência perfeita - o ajustamento das empresas ao novo custo mais alto da mão-de-obra, no curto prazo, faz-se via redução nos níveis de emprego e de produção, com esforços simultâneos no sentido de economizar trabalho direto por unidade de produto. O resultado desse ajustamento é o padrão típico de curto prazo, consistente com os modelos "clássico" e key-

4 Referimo-nos especificamente à regra do "mark-up", cuja relevância empírica para a formação dos preços no setor industrial das economias capitalistas contemporâneas é conhecida. Sobre o assunto consultar o cap. 12 de Koutsoyiannis (1975).

Na verdade, no 2 . ano de funcionamento da nova política salarial isto provavelmente foi conseguido, uma vez que a PRS aumentou, conforme a Tabela I mostra. Para um cálculo sobre o comportamento da taxa de lucro nessas circunstâncias, consul tar Moraes (1982, b).

6

Existem vários trabalhos que usam esse tipo de hipótese para analisar fenómenos relacionados com inflaçáo, polftica económica e salários. Dois ótimas exemplos såo fornecidos por Arida (1981) - Lara Resende e Lopes (1981). 
nesiano (bastardo ou não), no qual o salário real varia na direção inversa do nível de emprego. Quanto ao efeito sobre a demanda agregada, se abstrairmos os componentes associados às categorias de renda não derivadas do trabalho, e se acreditarmos, tal como Keynes, que

"A cada volume de $\mathrm{N}$ (emprego) corresponde certa produtividade marginal da mão-de-obra nas indústrias de bens de consumo dos assalariados, e é isto que determina o salário real". Keynes (1936, p. 41).

então, o efeito líquido sobre a demanda efetiva dependerá da elasticidade da demanda por mão-de-obra no mercado de trabalho. Se ela for elástica, teremos uma redução na demanda efetiva e vice-versa. A possibilidade de uma recuperação do nível de emprego via aumento de demanda repousa, portanto, nesta condição. Além disso, para que a hipótese com que estamos trabalhando - taxa de inflação constante não seja violada, é necessário que a oferta agregada seja perfeitamente elástica aos níveis de produção em que a economia estiver operando.

Agora, se abandonarmos essa hipótese irrealista e permitirmos que a taxa de inflação sofra uma aceleração para repor exatamente as margens de lucro das empresas - que, neste caso, detém poder de monopólio - o salário médio real no ano permanece inalterado e temos a manutenção dos níveis de emprego e produção. Além disso, se acreditarmos na hipótese keynesiana de ilusão monetária por parte dos assalariados, é possível esperar uma expansão temporária no nível de atividade da economia. Do lado da demanda agregada, poderia ocorrer uma expansão se as expectativas fossem "não-racionais", o que geraria uma pressão inflacionária adicional. Neste segundo caso extremo, portanto, o ajustamento faz-se via preços, enruuanto que no caso anterior, o ajustamento faz-se via quantidades. Como o mais provável quie ocorra é uma combinação de ambos os tipos de ajustamentos, podemos deduzir a seguinte condição: se a aceleração inflacionária for tal que a taxa instantânea de inflação sofra um acréscimo inferior ao dobro da taxa vigente, os prováveis efeitos serão um aumento do salário médio real no ano e uma redução no nivel de emprego e produção: por outro lado, se a nova taxa de inflação for maior do que o dobro da taxa antiga, os efeitos prováveis serão contrários $^{7}$.

Podemos agora perguntar: o que aconteceu no caso real da experiência brasileira recente? Examinando os dados sobre a inflação no Brasil em períodos de 12 meses antes e depois da implantação da nova política sala-

7 O valor do acréscimo é determinado por Moraes (1982 a,p.12). 
rial e calculando as perdas relativas de salário chegamos aos dados indicados na Tabela $\mathrm{I}^{8}$. Observando esses resultados, acreditamos que dois pontos podem ser ressaltados. (i) Qualquer que tenham sido a(s) causa(s) da aceleração inflacionária ocorrida durante a implantação da nova política salarial ela não conseguiu anular completamente o efeito de redução da PRS derivado da mudança de periodicidade no reajuste salarial - embora, no período abril 80 - abril 81, tenha conseguido até aumentar a PRS. (ii) Mesmo assim, apesar do patamar de PRS situar-se abaixo do vigente durante o reajuste anual (abril 78 - abril 79), o efeito de redução foi grandemente compensado pela aceleração da inflação, já que a PRS consistente com a taxa anual de inflação de $46,69 \%$ - sob o regime semestral - seria de apenas $8,99 \%$. Em outras palavras, e em termos da Figura II, a taxa de inflação pós-reajuste semestral oscilou entre valores abaixo e acima da taxa $r_{1}$, fazendo com que a economia tenha se deslocado dûravés de uma trajetória mais próxima da linha $A B$ do que da linha $A A^{\prime}$. Quanto aos níveis de emprego e produção, conforme os dados da Tabela A.4 (no Apêndice) indicam, o padrão verificado foi de crescimento ou estabilidade em 1979 - 80 simultâneo à aceleração

TABELA I:

PERDAS RELATIVAS DE SALARIO REAL (PRS) DEVIDAS A INFLAÇAO (\%, a.a.) ANTES E DEPOIS DA INTRODUÇȦO DO REAJUSTE SEMESTRAL DE SALÁRIOS NO BRASIL

Período

Abril 78 - Abril 79

Abril 79 - Abril 80

Abril $80-$ Abril 81

Abril 81 - Abril 82
Taxa de Inflação do Período ${ }^{1}$

PRS $^{2}$
1

2

A partir do IGP/DI, publicado em Conjuntura Econômica.

O método de cálculo aplica-se rigorosamente aos que recebem 11,5 MSMP (Maiores Salários Minimos do Paísl e supõe uma tạxa de inflação uniformemente distribuída no tempo. Já que ocorreu uma aceleraçăo da inflação, principalmente nos períodos intermediários, o método subestima o PRS ocorrido. Para maiores detalhes, consultar Moraes (1982.a).

8 E importante ressaltar que o método de cálculo usado, tal como indicado baixo da Tabela 1 tem suas limitaçőes, sendo a maior delas, obviamente, a abstraçáo da diferenciaçăo dos reajustes salariais o que implica a superestimaçáo do PRS dos assalariacios da faixa o - 11,49 MSMP e a subestimaçáo do PRS dos que recebem acima de 11,5 MSMP. 
da inflação, com uma reversão acentuada em 1981, ano em que tivemos a maior recessão do pós-guerra com uma taxa negativa de variação do PIB real. Parece fora de dúvida de que esta última foi causada, em grande parte, pela forte restrição monetária adotada a partir do $2^{\circ}$. Semestre de 1980 e durante a maior parte de 1981, embora não seja fora de propósito especular-se se também por-trás dessa recessão não haja um efeito retardado da nova política salarial. Para discutir esta última hipótese, no entanto, seria neces. sário levar em conta as diferenciações nos reajustes. Por este motivo, deixaremos esta discussão para a Parte 3.

Voltando à questão da aceleração inflacionária, caberia a pergunta: em que medida ela foi causada pela implantação da nova poítica salarial? A resposta a esta pergunta depende de uma análise cuidadosa da conjuntura em que a nova política foi introduzida. Macedo (1981, pp. 12-30), após examinar dados trimestrais do periodo 1977-79, conclui que a aceleração ocorrida na inflação - que tem in ício a partir do quarto trimestre de 1978 - antecedeu à implementação dos reajustes semestrais de salário. E no terceiro trimestre de 1979, no entanto, que se acentua este impulso inflacionário, sendo ele perfeitamente explicável pelo comportamento dos preços dos produtos de alimentação que conduziu a uma pressão pela expansão do crédito ao setor privado, o qual veio sancionar a tendência altista. Por outro lado, nc trimestre em que a nova política salarial foi implantada, o preço da gasolina comum sofreu um aumento anual de $108,7 \%$, quando no trimestre anterior o acréscimo havia sido apenas de $42,4 \%$. Este aumento foi acompanhado de uma aceleração adicional da taxa de inflação passando de $53 \%$ a.a. no terceiro trimestre de 1979 para $69,5 \%$ no quarto trimestre desse ano. Élícito supor, portanto, que a implantação da nova política salarial não foi "a" causa - nem a principal e nem a iniciadora - do recente surto inflaciónário. Ela serviu, no máximo, para reforçar uma tendência já existente decorrente de problemas de oferta agrícola e dos efeitos do 2 . choque do petróleo. Além disso, se levarmos em consideração as medidas de política econômica adotadas nesse período - a pré-fixação da correção monetária, por exemplo - cujos resultados foram opostos aos desejados, teremos um cenário no qual tantas forças expansionistas de demanda e de custos se fazem presentes que se torna totalmente impossível singularizar um fator como o responsável pela aceleração da inflação. Lara Resende e Lopes (1981) arriscam uma explicação. Segundo eles, a taxa de inflação de 1980 - medida pelo lindice de Preços no Atacado - Disponibilidade Interna - teve os seguintes componentes: (i) a taxa de inflação de $1979(=55,5 \%)$; (ii) o choque externo do petróleo $(=24,0 \%)$ e (iii) o impacto da nova política salarial $(=20,3 \%)$, totalizando uma taxa estimada de $99,8 \%$ para 1980 , quando a observada foi de $103 \%$. 
Ou seja, na ausência da implantação da nova pol ltica salarial, a taxa de inflação teria aumentado - em decorrência do $2^{\circ}$ choque do petróleo - para um patamar de $80 \%$. Devido aos efeitos de sua implantação, no entanto, o novo patamar veio a ser de $100 \%$. Se aceitarmos esses resultados, podemos retirar algumas implicações importantes. Em primeiro lugar, o impacto da nova política salarial não é a explicação única para a aceleração verificada, embora tenha contribuído para reforçar um impulso inflacionário pré-exis. tente. Em segundo lugar, se retiramos o efeito estimado do choque externo, a variação provocada na taxa de inflação não teria sido suficiente para anular a redução na PRS decorrente da mudança na periodicidade do reajuste. Em terceiro lugar, se comparamos a situação verificada em $1980 \mathrm{com}$ uma hipótese alternativa de presença dos efeitos do choque externo mas sem alteração na pol ftica salarial - o que geraria uma inflação em torno de $\mathbf{8 0} \%$, segundo a estimação - teríamos, claramente, uma queda no salário médio real devido à aceleração da inflação, o que não se concretizou na extensão em que o seria porque o reajuste semestral foi in troduzido $^{9}$.

Outro aspecto relevante que deve ser considerado é um elemento apontado por Carvalho (1981) e Macedo (1981) e que se constitui na mudança de comportamento do Governo na área de controle de preços por ocasião da introdução dos reajustes semestrais de salários. Esta ação "...., em lugar de evitar o repasse, apressou-se em estabelecer explicitamente regras que vieram a facilitar a sua ocorrência". (Macedo, 1981, p.24). Conseqüentemente, o mecanismo de ajustamento via preços das empresas aos "choques" do petróleo e do salário foi facilitado pelo próprio governo.

0 cenário até aqui desciito indica que, abstraindo a diferenciação dos reajustes salariais, a passagem do regime anual para o regime semestral acarretou - devido a pressões inflacionarias que se somaram, incluindo as decorrentes da mudança na periodicidade - variações mínimas no nível de salário médio real. Mais adiante voltaremos a este ponto.

\section{OS EFEITOS DA DIFERENCIAÇÃO NOS REAJUSTES}

Nesta parte ignoraremos a periodicidade e estudaremos os efeitos esperados da diferenciação nos reajustes. A estrutura das taxas diferenciadas de reajuste e a mecânica do cálculo para as várias faixas salariais possuem 9 A PRS calculada para uma inflação de $80 \%$ a.a. com reajuste anual é de $24,38 \%$ enquanto que
a calculada para uma inflação de $100 \%$ com reajuste semestral é de $15,38 \%$. 
várias propriedades matemáticas que foram esclarecidas por vários autore ${ }^{10}$ Dentre essas propriedades deve-se ressaltar as seguintes:

(i) os salários altos tendem a diminuir e os salários baixos a aumentar, convergindo, com o tempo, para o valor de 11,5 MSMP.

(ii) a velocidade de convergência de qualquer salário para o valor aci. ma indicado é uma função crescente da taxa de inflação.

(iii) a velocidade de convergência -- dada uma taxa de inflação constante - é bem maior nas faixas mais altas.

(iv) a pressão de custo sobre a folha de pagamentos derivada da aplicação da política salarial depende da distribuição dos empregados nàs faixas sa. lariais, sendo uma função crescente da proporção de assalariados situados nas faixas mais baixas ${ }^{11}$.

Antes de comentarmos essas propriedades e algumas das simulações efetuadas, convém deixar claro que o objetivo implícito de uma lei que gera uma estrutura com essas propriedades é claramente redistribuir a renda dos assalariados à la Robin Hood ${ }^{12}$. Na ausência de uma série de ajustamentos que, teoricamente, podem anular o efeito redistributivo almejado - e que serão mencionados mais adiante - a operação dessa estrutura ao longo do tempo conduziria a uma distribuição de salários com perfeita igualdade. Segundo Baumgarten (1981, pp.328), para uma taxa semestral constante de INPC igual a 40\%, esta situação ocorreria não antes do que daqui a 121 semestres, embora os-salários mais altos já estejam na vizinhança de 11,5 MSMP Jaqui a menos do que 20 semestres. Esta disparidade nas velocidades de convergência entre os salários mais altos e os mais baixos tem como efeito fazer recair o impacto inicial da política salarial sobre ns assalariados de mais alta renda, suavizando a pressão sobre a folha de pagamentos para os empregadores. Porém, a medida em que a estrutura da foina se altera com o decorrer do tempo - aumentando a proporção dos assalariados de baixa renda - cada vez mais os ganhos reais desses assalariados terão de ser oriundos de transferências reais de Jucros. Esta questão relaciona-se diretamente com uma discussão presente na já numerosa literatura a respeito da política salarial: dada a folha de pagamento efetiva da economia brasileira, a estrutura

\footnotetext{
10 Para a verificação das fórmulas de reajuste ditadas pela lei de acordo com as faixas salariais, consul tar Camargo (1980, pp. 974-982). Macedo (1981, pp. 6-12) ou Baumgarten (1981, pp. 320-327).

11 Para as propriedades (i) e (ii), consul tar os artigos citados na nota 9. Para a propriedade (iii), con sultar especialmente Baumgarten (1981) e para o item (iv), consultar especialmente Camargo (1980) e Carvalho (1982).

12 Um Robin Hood muito respeitoso com as grandes empresas mas nada respeitoso com os assalariados de mais al ta renda, como veremos nais adiante.
} 
de taxas de reajuste da política salarial é inflacionária? A discussão é relevante porque, dado que existe a propriedade (iv) acima, seria perfeitamente possível imaginar que a distribuição dos assalariados fosse tal que a aplicação da lei gerasse um crescimento da folha de pagamentos total inferior à taxa do INPC, o que configuraria uma redução real da folha e, portanto, uma redução do custo real do trabalho. Esta hipótese foi originalmente proposta por Camargo (1980) e rapidamente encontrou adeptos entre os defensores da poIftica salarial. Os dados que deram credibilidade a ela foram os da RAIS-76 e que, apresentados por Camargo, indicaram, por exemplo, que o reajuste da folha de pagamentos seria inferior à taxa do INPC nas empresas com mais de 100 empregados na indústria e no comércio, sendo, para o conjunto da indústria igual à taxa do INPC e para serviços, inferior. Carvalho (1982) também efetuou o mesmo tipo de exercício, com os mesmos dados, confirmando em parte os resultados, mas achando uma variabilidade significativa entre setores. Por exemp!o, para "Vestuário, Calçados e Tecidos", o efeito total seria 7,46\% acima do iNPC. De qualquer forma, o "comércio" sempre apresentou taxas superiores ao INPC, assim como as pequenas empresas - no estudo de Carvalho, as empresas com até 250 empregados na "Indústria" e no "Comércio".

A partir desses dados, Camargo sugeriu que sendo as grandes empresas as "price-makers" e sendo elas as que tem seus preços controlados, a taxa de inflação não seria pressionada pela aplicação dos reajustes diferenciados, a não ser em um período de transição. Passado este periodo, a tendência seria de a taxa de inflação ser reduzida já que os reajustes seriam inferiores ao INPC. Em compensāção, as pequenas empresas, cujas folhas são reajustadas acima das taxas do INPC, seriam seriamente afetadas, tendo seus lucros reais reduzicios e, eventualmente, sendo absorvidas pelas maiores. $\mathrm{De}$ onde, $\mathrm{Ca}$ margo imaginou três tipos de efeitos da política salarial: (a) um efeito antiinflacionário; (b) um efeito concentrador da propriedade no setor industrial; e (c) um efeito redistributivo funcional da renda. Por ora, o que nos interessa é a plausibilidade do primeiro efeito. Voltando à pıopriedade (iii) que discutia acima - sabemos que os salários altos rapidamentes cairão enquanto que os salários baixos lentamerite subirão. Se as empresas fossem homogêneas quanto à estrutura de sua folha de pagamentos, todas elas arcariam com um custo real do trabalho cuja trajetória temporal seria caracterizada por uma linha crescente de igual inclinação, tal como dissemos anteriormente. No entanto, dada a heterogeneidade por tamanho e setor apontada por Camargo; vimos que o grosso do impacto inicial da política salarial foi - ou está sendo - compartilhado de forma desigual entre as empresas. Nas pequenas - abstraindo al terações no emprego - o custo real da folha tem aumen- 
tado, enquanto que, nas grandes, o custo real inicial diminuiu - em relação à polftica anterior e abstraindo a mudança na periodicidade - fazendo com que o efeito "Robin Hood"sobre os salários seja perversamente sustentado, no lado empresarial, por um mecanismo de transferência de renda real que tira das pequenas e médias empresas para pagar os acréscimos reais de suas folhas e reduz o custo real das folhas das grandes empresas, pelo menos no in ício. Passado este impacto inicial, no entanto, a tendência é de aumentar o custo real do trabalho para todas as empresas. Este último elemento é o que tem sido ignorado pela maioria dos trabalhos sobre o assunto, onde as simulações sãofeitas para níveis arbitrários de salários ${ }^{13}$.

Para que tenhamos uma idéia - embora aproximada - da variação na pressão de custo real decorrente da política salarial, é necessário incorporarmos a mudança ao longo do tempo no perfil da folha efetiva causada pelos reajustes salariais sucessivos. Esta mudança - dadas as propriedades (i)-(iv) acima ocorre, tal como foi indicado por Baumgarten (1981, pp. 330-332), na direção de aumentar a pressão de custo da folha de pagamentos até atingir um patamar de 1,08 INPC (a taxa de reajuste efetiva da folha) após 10 semestres de execução da política, permanecendo em torno deste valor por um longo período, antes de declinar, convergindo para 1,0 INPC. Com a finalidade de observar este comportamento, efetuamos algumas simulações, cuja metodologia e resultados estão no Apêndice. Podemos ver, pela Tabela A.1, que as duas faixas de salários mais baixo e cujos reajustes são superiores aos do INPC, incluíam - em dezembro de 1979 - 96,21\% do emprego total e $76 \%$ do valor da foina total. Efetuando a simulação apresentada na Tabela A.2, observamos que a evolução do salário médio de cada faixa apresentou taxas diferenciadas de variação. Em termos de MSMP, o salário médio da faixa 1 (0 - 3 MSMP) passou de 1,44 MSMP para 1,7 MSMP após 6 semestres de aplicação da política, enqua anto que o da faixa 5 (mais de $2 \mathrm{C}$ MSMP) passou de 32,24 MSMP para 18,86 MSMP no mesmo período, ultrapassando o limite inferior de definição da faixa 5. A Figura III dá uma idéia gráfica da trajetória desses salários médios em termos de MSMP. Isto ilustra as propriedades (i) - (iii) indicadas acima.

Pela Tabela A.3 podemos observar as variações nas participações relativas de cada faixa na folha total. No início do $7^{\circ}$ semestre, a faixa 1 está absorvendo $45,79 \%$ quando, no primeiro, ela participava com apenas $40,83 \%$. Já a faixa 5 - dada a hipótese que adotamos, segundo a qual todos os assala-

13 Um exemplo disto é o de Carvalho (1982) que só leva em conta a folha de pagamentos efetiva da economia brasileira para avaliar o impacto inflacionário inicial, ignorando os dados reais para as simulações de comportamento dos salários para o fıturo. 


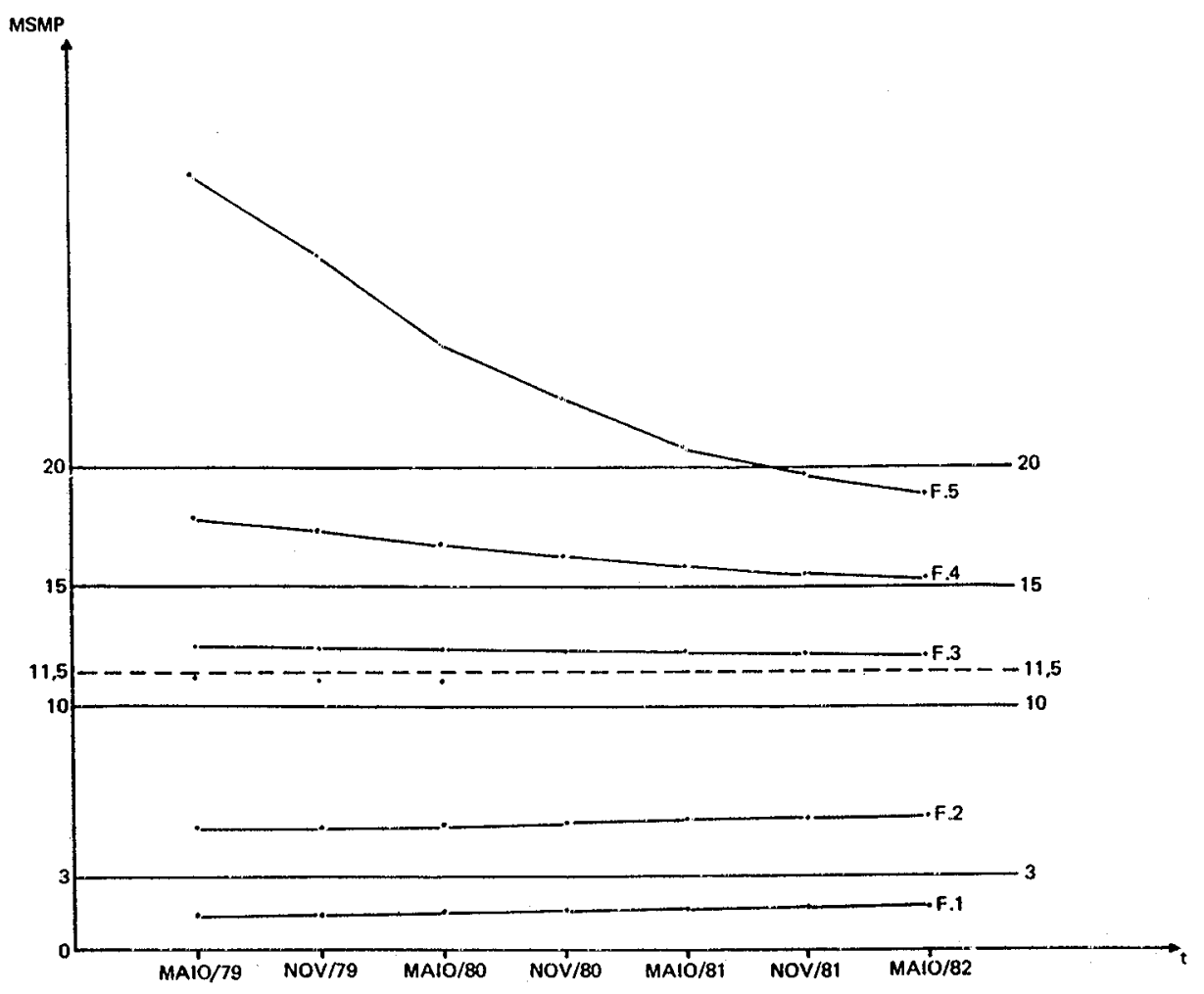

FIGURA III

riados de cada faixa recebem o salário médio da faixa respectiva - desaparece no 6 . semestre. Se somarmos as faixas 1 e 2 , considerando-as de "salário baixo", e as faixas 4 e 5 , chamando-as de "salários altos", verificaremos que em, 6 semestres, o grupo de "salário baixo" passa de uma participação relativa de $74,66 \%$ da folha total para $81,15 \%$, enquanto que o de "salário alto", no mesmo período passa de $16,19 \%$ para $10,38 \%$, totalizando, portanto, urn efeito redistributivo na ordem de aproximadamente $6 \%$ da follha total. A Figura IV dá uma idéia visual de mudança ocorrida na distribuição da folha de pagamentos por faixas salariais de maio de 1979 a maio de 1982 sob as hipóteses indicadas no Apêndice. Esta mudança ilustra o argumento mencionado de Baumgarten e é uma conseqüência das propriedades (i) - (iv). Para verificarmos como a variação ao longo do tempo no perfil da folha afeta o valor real da folha (determinado pelo deflacionamento do valor nominal da folha pelo índice de variação do MSMPI, consiruímos a tabela A.6. Os resultadcs que ora nos interessam estão na coluna 4 dessa tabela, cuja representação gráfica 


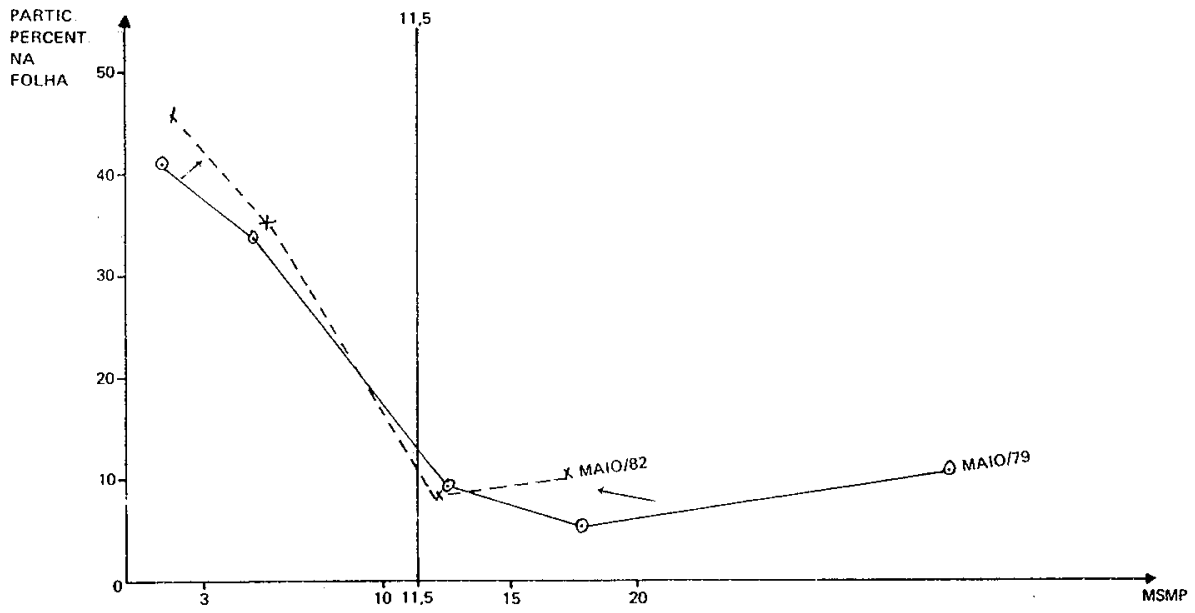

FIGURA IV

é feita pela linha $F \bar{C} C$ da Figura $V$. Podemos verificar que o índice de valor real cresce ao longo do tempo, embora inicialmente, as variações sejam mínimas. Isto ilustra novamente o argumento de Baumgarten e cujas conseqüências já mencionadas merecem ser repetidas. Dada a estrutura inicial da

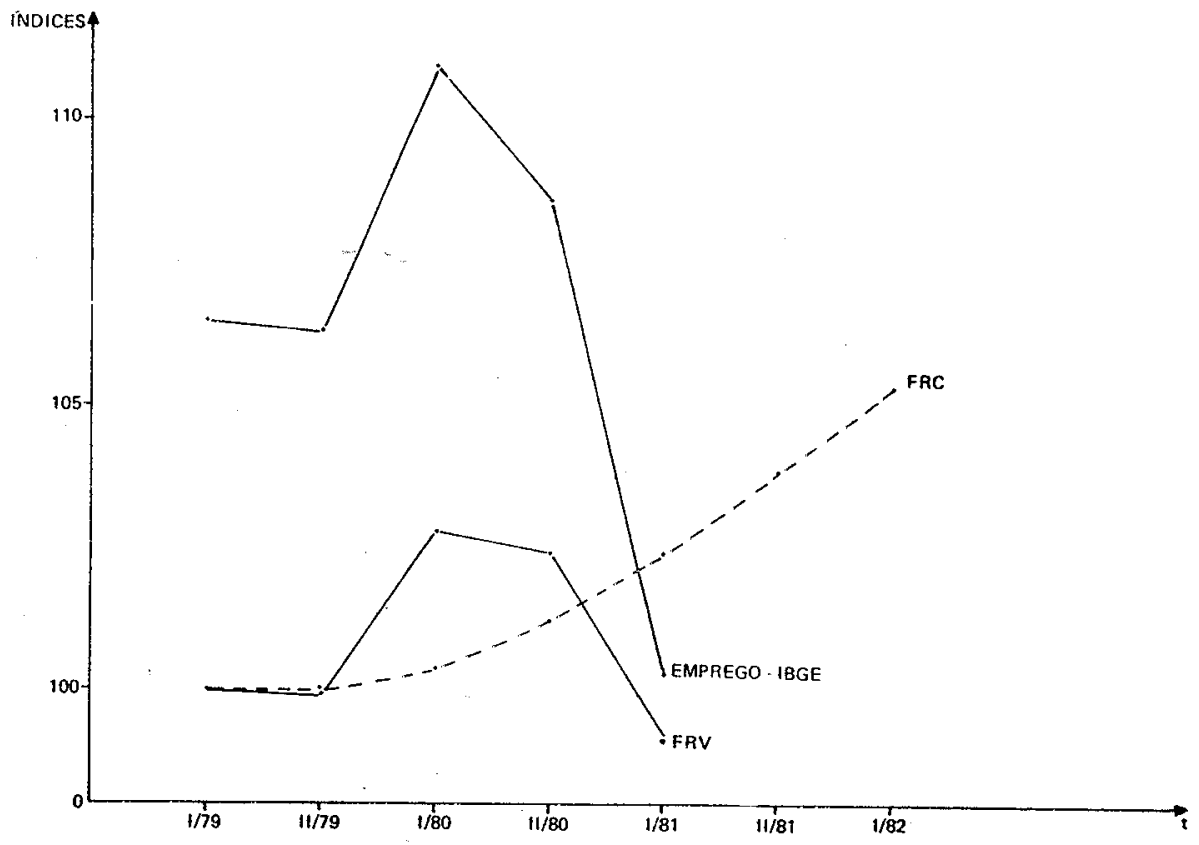

FIGURA V 
folha de pagamentos efetiva da economia brasileira, a aplicação das taxas diferenciadas de reajuste da política salarial não exerceu impacto significativo em termos de custo real do trabalho - abstraindo a mudança de periodicidade e a heterogeneidade por tamanho e setores já mencionados - apenas nos reajustes iniciais. A medida em que o perfil da folha muda, o impacto, em termos de aumentos de custo real, aumenta para todas as empresas. No caso da Tabela A.6, a folha de pagamentos, em termos reais, está 5,29\% acima do valor inicial 6 semestres após.

Todos os resultados encontrados por esta simulação que acabamos de examinar dependem da hipótese adotada segundo a qual o emprego total manteve-se constante ao nível de dezembro de 1979. Quando levamos em conta as variações ocorridas no nível de emprego na forma em que está explicada nas tabelas A.4 e A.5 do Apêndice, alguns resultados são alterados. Inicialmente, devemos chamar a atenção para um detalhe importante. Toda a variação estimada no emprego total (tabela A.4) foi imputada à faixa 1. A razão para isto reside em dois argumentos básicos. Em primeiro lugar, as próprias taxas diferenciadas de reajuste salarial e que implicam o crescimento do preço relativo do trabalho menos qualificado. Neste sentido, e paradoxalmente, as empresas seriam induzidas a economizar trabalho mais barato para minimizar o crescimento real da folha de pagamentos ${ }^{14}$. Este mecanismo "neoclássico" de ajustamento equivaleria a um efeito-substituição na composição do emprego. Em segundo lugar, e como é conhecido na

14 Para demonstrar este ponto façamos com que sejam:

$W_{0}=o$ maior salário mínimo do país no instante zero.

$\mathrm{K}_{\mathrm{i}}{ }_{\mathrm{O}}=$ quantos MSMP vale o salário médio da $i$-ésima faixa salarial.

$\mathrm{C}_{\mathrm{i}}{ }^{-}=$coeficiente cie reajuste do salário médio da i-ésima faixa, dado pela estrutura de taxas diferenciadas da política salarial.

$L_{j}(t)=$ número de assalariados empregados na $i$ ésima faixa salarial.

$W_{t}=$ o valor do MSMP no instante $t$

$r$ a taxa instan tânea de inflação.

$F_{t}=$ total da folha de pagamentos no instante $t$ em cruzeiros correntes.

$f_{t}{ }^{t}=$ total da folha ein termos reais; deflacionado pelo indice do MSMP.

Então:

(1) $F_{i}=\sum K_{i} W_{0} \beta^{c_{i} r t} L_{i}(t)$

(2) $w_{t}=w_{g} e^{r t}$

e a folha de pagamentos, em termos reais sera

(3) $f_{t}=\sum K_{i} L_{i}(t) e^{\left(c_{i}-1\right) r t}$

onde podemos ver que se $C_{i}>1$ (salários baixos) a contribuição da $i$-ésima faixa aumenta com o. tempo, dados o nivel de emprego e a taxa de inflação, ao passo que, se $\mathrm{C}_{i}<1$, a contribuição da faixa diminui com o tempo, dados o nivel de emprego e a taxa de inflação. 
literatura sobre Economia do Trabalho - ponto ressaltacio por Silva (1982, pp.83-84) - em épocas de recessão (como o periodo abrangido pela Tabela A.4), as empresas tentam reter os empregados mais antigos e/ou aqueles cujo treinamento no próprio emprego requer mais tempo, além, naturalmente, dos quadros administrativos. Este comportamento conduz a que, normalmente , a variação no emprego que absorve o impacto da recessão se dê através de demissões de empregados de salários mais baixos. Estas duas razões, conjuntamente, nos conduzem a supor que a hipótese adotada é bastante plausível. Observando, na Tabela A.5, verificamos que, quando levamos em consideração a variação no emprego total, os efeitos redistributivos - medidos pelas variações nas participações relativas nas diversas faixas - - são consideravelmente reduzidos: a faixa 1 atinge $42,68 \%$ da folha em maio 81 contra $44,48 \%$ na hipótese anterior. Já, a faixa 5 mantém $7,13 \%$ em maio de 81 contra $6,9 \%$ na hipótese anterior. Obviamente, este resultado depende completamente da plausibilidade da hipótese discutida anteriormente. Deve-se ressaltar, no entanto, que o efeito redistributivo não é anuladio. Uma implicação mais importante - e que al tera significativamente os resultados encontrados - é o efeito que esta variação no emprego produz sobre o comportamento da folha de pagamentos em termos reais. Observando a coluna 6 da Tabela A.6 e a sua representação gráfica na Figura V - curva FRV - vemos que o padrão, de certa forma, é invertido em relação à hipótese anterior. Isto sugere que -- se a hipótese de variação no emprego sendo absorvida na faixa 1 for verdadeira o desemprego funcionou, pelo menos nesse período, como mecanismo de impedir o aumento real da folha via al teração invertida - em relação ao padrão conseqüente da repetida aplicação da política salarial - da composição do emprego por faixas salariais. É neste sentido que a afirmação feita na Parte 2 -- segundo a qual não seria fora de propósito imaginar na recessão de 81 , pelo menos em parte, um efeito retardado na aplicação da política salarial se justifica ${ }^{15}$.

Cutro resultado interessante que surge da comparação das duas simulações feitas refere-se ao comportamento do salário médio real. A Tabela A.7 indica que ele cresce sob as duas hịpóteses mas com uma diferença marcante: com emprego constante ele se mantém crescendo monotonicamente, enquanto que, com emprego variável, ele decresce no único período em que houve aumento de emprego e aumento em todos os demais. Além disso, o aumento de $5,0 \%$ verificado no último periodo para o qual havia dados em

15 Outro mecanismo gerador de desemprego que teria sido acionado pela aplicação da pol itica salarial é apontado por Baumgarten $(1981$, p.332) e consiste no efeito contracionista sobre a deminda agregada que a redução rápida no poder aquisitivo dos salários mais altos teria gerado. 
relação ao período base, foi inteiramente conseguido exatamentc no período em que o índice de emprego despenca. Isto reforça o ponto levantado por Silva (1982, pp.83-84) de que o aumento do salário médio real na conjuntura recessiva deve-se à redução no emprego que atinge as faixas de salário baixo.

Retornando, agora, aos efeitos previstos por Camargo para a politica salarial, cremos que temos razões para suspeitar de que o único que não nos parece plausível é o efeito anti-inflacionário, devido aos argumentos até aqui apresentados. Quanto aos efeitos redistributivos, cremos ser fora de dúvida que (a) a distribuição pessoal de salários na folha tende a se tornar menos concentrada, (b) a distribuição funcional de renda tem sido e continuará sendo cada vez mais afetada, gerando transferências reais de lucros para os salários e, finalmente, (c) que estes efeitos tem sido assimetricamente sustentados - o peso inicial da aplicação da política salarial recaiu sobre os assalariados de altos salários, como mostra a Figura III, e sobre as pequenas e médias empresas, o que pode estar gerando uma concentração maior nos setores secundário e terciário da economia.

Quanto ao desemprego observado, cremos que ele apresenta várias questões. Existem razões - já mencionadas -- para acreditar que parte do desemprego tenha sido causado pelos efeitos da política salarial. Este efeito desemprego, assim como o efeito inflacionário, precisam ser computados na conta da política salarial para que se avalie corretamente os seus efeitos totais. E possível imaginar um efeito desemprego tão poderoso que anule os benefícios redistributivos derivados da política salarial. Afinal de contas, de que adianta uma redução na dispersão dos salários se grande parte dos assalariados de baixa renda perdem seus empregos? O que complica o cômputo deste efeito é que o desemprego conjuntural que ocorre no período analisado não pode ser atribuído somente aos efeitos da política salarial, como já foi mencionado.

Cremos que os principais pontos relacionados com as diferenciações nos reajustes foram discutidos nesta parte, embora não tenhamos chegado a conclusões inequívocas em todos eles.

\section{CONSIDERAC̣ŌES FINAIS}

A decomposição efetuada do pacote da política salarial em dois componentes - a mudança de periodicidade e a diferenciação nos reajustes justifica-se apenas como um recurso anal ítico. Obviamente, o impacto sobre a economia resulta da aplicação simultânea dos dois componentes. Do que discutimos acima, resta saber se os efeitos esperados de um componente es- 
tão na mesma direção dos efeitos esperados do outro componente. Sob esse ponto de vista, cremos que não há nenhuma contradição no pacote. O objetivo da mudança de periodicidade foi reduzir as perdas reais de salário devidas à aceleração da inflação. Vimos que os mecanismos de ajustamento da economia em resposta a essa tentativa - apenas parcialmente bem sucedi-da - implicaram aceleração da inflação e/ou aumento no desemprego. De qualquer modo, uma vez que essas perdas reais tenham sido diminuídas e o foram no período mais recente como indica a Tabela 1 - existe um efeito redistributivo real cuja direção é dos lucros para os salários. Por outro lado, os objetivos da diferenciação dos reajustes - redistribuição progressiva da folha salarial e suavização do impacto inflacionário inicial - não estão em contradição com os efeitos esperados da mudança de periodicidade. Tampouco se pode dizer que os mecanismos de ajustamento da economia em resposta à taxas diferenciadas sejam opostos aos acionados pela mudança de periodicidade, já que, como vimos, eles implicaram apenas uma alteração na ordem de grandeza dos efeitos inflacionários e de desemprego. Deve-se ressaltar, no entanto, que se a hipótese do efeito substituição no emprego for vălida, existirá um componente alocativo novo não desencadeado pela simples mudança de periodicidade.

$E$ importante explicitar ainda que todos esses efeitos esperados dependem de duas hipóteses cruciais. A primeira é de que os reajustes do MSMP realmente reflitam as variações no indice do custo de vida da economia. Se isto não ocorrer, podemos ter uma redução do salário médio real ao longo do tempo. Em segundo lugar, é crucial que a rotatividade da mão deobra - a qual pode ser um mecanismo de não aplicação da política salarial não sofra grandes alterações ${ }^{16}$.

Finalmente, gostaríamos de deixar claru que o ohjeíivo do presente trabalho foi de estudar desapaixonadamente os efeitos da nova política salarial. A impressão final que esse estudo nos deixa é de que essa política foi apenas parcialmente bem sucedida e que, dados os efeitos previsíveis para o futuro, ela será alterada em alguns pontos. Queremós deixar claro, também, que é nossa convicção que se, para a obtenção de alguns benefícios para os assalariados foram gerados alguns custos importantes com a aplicação da política salarial, o seu abandono completo agora -- com uma reversão ao sistema anterior - seria inequivocamente prejudicial aos assalariados, uma vez que os mecanismos de ajustamento que funcionaram para suavizar os

16 Embora pouco estudada, existem indicios de que ela aumentou após a aplicação da política salarial. Consultar Souza (1980). 
efeitos sobre os não-assalariados - e que implicaram, em parte, um repasse de custos para os próprios assalariados - não funcionam para suavizar os efeitos de um retorno ao status quo ante.

\section{APENDICE}

O objetivo deste apêndice é explicar detalhadamente a metodologia adotada na confecção dos dados em que se baseiam as figuras e tabelas referentes à Parte 3 deste artigo.

TABELA A.1:

EMPREGOS REGIDOS PELA CLT EM 31/12/79

\begin{tabular}{lrrrc}
\hline $\begin{array}{l}\text { Faixas } \\
\text { Salariais }\end{array}$ & Emprego & $\begin{array}{c}\text { Partic. no } \\
\text { emprego (\%) }\end{array}$ & $\begin{array}{c}\text { Salário } \\
\text { Médio * }\end{array}$ & $\begin{array}{c}\text { Participação } \\
\text { na Folha (\%) }\end{array}$ \\
\hline Até 3 MSMP & 10.412 .999 & 77,64 & $4.343,37$ & 41,73 \\
$3 \cdot 10$ & 2.490 .589 & 18,57 & $14.913,04$ & 34,27 \\
$10-15$ & 262.579 & 2,01 & $36.545,35$ & 9,09 \\
$15 \cdot 20$ & 109.977 & 0,82 & $50.949,86$ & 5,17 \\
mais de 20 & 124.730 & 0,93 & $84.285,94$ & 9,7 \\
\hline TOTAL & 13.407 .874 & 100,00 & $8.083,40$ & 100,0 \\
\hline
\end{tabular}

* em cruzeiros correntes

Esta tabela foi construída com base nos dados da RAIS/76, citados no artigo de Baumgarten, nas pps. 330-331. Ele apresenta os totais da folha e do emprego, p.330, e uma tabela com as participações relativas contidas na tabela A.1 acima. Usando esses dados, foram calculados o n. de empregados em cada faixa e o salário médio. Devido ao arredondamento implícito neste procedimento total de emprego acima (13.407.874) é levemente inferior ao citado por Baumgarten (13.411.900), o que não afeta os resultados encontrados.

A Tabela A.2 foi construída a partir dos dados da Tabela A.1 e aplicando sobre aqueles valores do salário médio as fórmulas de reajuste da política salarial, as quais pcdem ser encontradas em Baumgarten (op. cit. pp.332-327) e Macedo (op. cit. pp. 7-12). Neste cálculo não foi incluído 
nenhum aumento de produtividade, apenas o reajuste do INPC. A taxa considerada deste último foi a do reajuste efetivamente realizado no MSMP na época correspondente. As colunas de MSMP na Tabela A.2 representam apenas o quociente do salário médio vigente no período indicado para a faixa correspondente pelo MSiMP do mesmo período.

TABELA A.2:

EVOLUÇAOO DO SALARIO MEDIO DAS 5 FAIXAS SALARIAIS EM CRUZEIROS CORRENTES, EM TERMOS DO MAIOR SALARIO MINIMO DO PAIS (MSMP): MAIO/79 - MAIO/82.

\begin{tabular}{|c|c|c|c|c|c|c|c|c|c|c|}
\hline \multirow{2}{*}{ PERÍODO * } & \multicolumn{2}{|c|}{ FAIXA 1} & \multicolumn{2}{|c|}{ FAIXA 2} & \multicolumn{2}{|c|}{ FAIXA 3} & \multicolumn{2}{|c|}{ FAIXA 4} & \multicolumn{2}{|c|}{ FAIXA 5} \\
\hline & Cr\$ & MSMP & $\mathrm{Cr} \$$ & MSPM & Cr\$ & MSMP & Crs & MSMP & crs & MSMP \\
\hline $1 / 79$ & $3.284,85$ & 1,44 & $17.379,49$ & 5,01 & $28,367,59$ & 12,50 & $40.498,12$ & 17,85 & $73.121,94$ & 32,2 \\
\hline $11 / 79$ & $.4 .343,57$ & 1,48 & $14.913,04$ & 5,08 & $36.545,35$ & 12,46 & $50.949,86$ & 17,37 & $84.285,94$ & 28,73 \\
\hline $1 / 80$ & $6.321,63$ & 1,52 & $21.451,29$ & 5,16 & $51,441,78$ & 12,39 & $69.752,89$ & 16,80 & $104.684,15$ & 25,22 \\
\hline $11 / 80$ & $9.068,37$ & 1,56 & $30.416,27$ & 5,25 & $71,467,29$ & 12,34 & $94.674,91$ & 16,35 & $132.220,89$ & 22,84 \\
\hline $1 / 81$ & $13.676,91$ & $T, 61$ & $45.270,91$ & 5,34 & $104,032,77$ & 12,29 & $134.730,90$ & 15,91 & $177.151,24$ & 20,92 \\
\hline $11 / 81$ & $19.830,15$ & 1,66 & $64.825,34$ & 5,43 & $146.035,12$ & 12,24 & $185.825,67$ & 15,57 & $235.314,57$ & 19,72 \\
\hline $1 / 82$ & $28.380,91$ & 1,70 & $91.639,60$ & 5,51 & $202.586,01$ & 12,19 & $254.042,77$ & 15,29 & $313.231,50$ & 18,86 \\
\hline
\end{tabular}

- 1/ano significa o valor vigente no período maio-outubro de qualquer ano, enzuanto que II/ano significa o valor vigente no per fodo novembroabril do ano seguinte.

A Tabela A.3 foi construida da seguinte maneira. Supondo que todos os assalariados de cada faixa recebam o salário médio de sua faixa, multiplicou-se o número de empregados de cada faixa (da Tabela A.1) pelo salário médio da faixa em cada período (da Tabela A.2) obtendo-se o valor em milhões de cruzeiros correntes. Como o salário médio da faixa 5 ultrapassa o limite inferior de sua faixa (20 MSMP) no 6. ${ }^{\circ}$ período considerado, agrupamos a parcela desta faixa com a faixa 4 nos dois últimos semestres.

TABEL.AA.3:

VALOR DA FOLHA DE PAGAMENTOS DA ECONOMIA BRASILEIRA POR FAIXAS SALARIAIS EM MILHOES DE CRUZEIROS CORRENTES COM O EMPREGO TOTAL DE OEZEMBRO/79 MANTIDO CONSTANTE.

\begin{tabular}{|c|c|c|c|c|c|c|c|c|c|c|c|}
\hline \multirow{2}{*}{ PERIODO } & \multicolumn{2}{|c|}{ FAIXA 1} & \multicolumn{2}{|c|}{ FAIXA 2} & \multicolumn{2}{|c|}{ FAIXA 3} & \multicolumn{2}{|c|}{ FAIXA 4} & \multicolumn{2}{|c|}{ FACXa 5} & \multirow{2}{*}{$\begin{array}{l}\text { TOTAL } \\
\left(C r E 10^{6}\right)\end{array}$} \\
\hline & $\operatorname{cr} \$ 10^{6}$ & PARTIC $(x)$ & $\operatorname{cr} \$ 10^{6}$ & PARTIC $(x)$ & $\operatorname{cr} \$ 10^{6}$ & PARTIC. $(x)$ & $\operatorname{crs} 10^{6}$ & PARTIC. $(x)$ & $C r \leqslant 10^{6}$ & PARTKC.(x) & \\
\hline $1 / 79$ & 34205.13 & 40,83 & $28.341,63$ & 33,83 & 7.647 .30 & 9,12 & $4,453,66$ & 5,31 & $0.120,49$ & 10,88 & $63.768,43$ \\
\hline $11 / 79$ & 45.229 .59 & 4174 & $37,142.25$ & 34,28 & $9.851,85$ & 9.09 & $5.603,31$ & 6,17 & 10.612 .98 & 9,70 & 108.339 .98 \\
\hline $1 / 80$ & 65.827 .12 & 42,78 & $53.426,34$ & 34,72 & 13.867 .62 & 9,01 & 7.671 .21 & 4,88 & 13.057 .25 & 8.48 & $163.649,64$ \\
\hline $\mathrm{J1} / 80$ & $94.428,92$ & 43,64 & $75: 754,42$ & 35,01 & $19.266,08$ & 8,8 & $10.412,06$ & 4.81 & $16.491,01$ & 7,62 & $216.353,39$ \\
\hline $1 / 81$ & $142,417,65$ & 44,48 & $112.751,23$ & 35.22 & 28.046 .06 & 8.76 & $14.817,30$ & 4,62 & $22,086,07$ & 6,90 & $320.127,3$ \\
\hline $\mid 1 / 81$ & 206.491 .33 & 45,17 & $161,453,27$ & 35,32 & $39,368,00$ & 8,61 & $49.787,32$ & 10,80 & - & - & 457.000 .02 \\
\hline J/EC & $295.530,38$ & 4679 & $228.236,57$ & 35,36 & $54.612,03$ & 8,46 & $67.068,22$ & 10,38 & - & - & $646.388,1$ \\
\hline
\end{tabular}


TABELA A.4:

INDICE GERAL DE EMPREGO E VALOR ESTIMADO DO NÜMERO TOTAL DE EMPREGADOS PELA CLT: MAIO 79 -MAIO 81.

\begin{tabular}{rrrr}
\hline Periodo & $\begin{array}{c}\text { indice de } \\
\text { emprego * }\end{array}$ & $\begin{array}{c}\text { N. estimado de } \\
\text { empregados }\end{array}$ & $\begin{array}{c}\text { Variação no emprego } \\
\text { total }\end{array}$ \\
\hline $1 / 79$ & 106,50 & 13.425 .522 & -17.648 \\
$I 1 / 79$ & 106,36 & 13.407 .874 & +579.881 \\
$1 / 80$ & 110,96 & 13.987 .755 & -289.941 \\
$I 1 / 80$ & 108,66 & 13.697 .814 & -1.051 .350 \\
\hline$/ 81$ & 100,32 & 12.646 .464 & -054 \\
\hline
\end{tabular}

* média semestial do Indice Geral de Emprego do IBGE publicado em Conjuntura Econômica.

A Tabela A.4 apresenta o valor médio semestral do lndice Geral de Emprego do IBGE publicado em Conjuntura Econômica e que tem 1976 como ano-base. Este índice foi usado para estimar as variações no emprego total a partir do dado disponível de dezembro/79 da Tabela A.1.

TABELA A.5:

VALOR DA FOLHA DE PAC NMENTOS DA ECONOMIA BRASILEIRA POR FAIXAS SALARIAIS, EM MILHOES DE CRUZEIROS CORRENTES, COM VARIACCOES NO EMPREGO TOTAL ABSORYIDAS NA FAIXA 1.

\begin{tabular}{|c|c|c|c|c|c|c|c|c|c|c|c|}
\hline \multirow{2}{*}{ PEAIODO } & \multicolumn{2}{|c|}{ FAIXA I } & \multicolumn{2}{|c|}{ FAIXA 2} & \multicolumn{2}{|c|}{ FAIXA 3} & \multicolumn{2}{|c|}{ FAIXA 4 } & \multicolumn{2}{|c|}{ FAIXA 6} & \multirow{2}{*}{$\begin{array}{c}\text { TOTAL. } \\
\left(\text { Crs } \$ 10^{6}\right)\end{array}$} \\
\hline & $\operatorname{Cr} \$ 10^{6}$ & PARTIC. $(x)$ & $C+10^{6}$ & PARTIC (x) & $C \$ 10^{6}$ & PARTIC. $(\mathbf{x})$ & $\cos \leqslant 10^{6}$ & PARTIC, $(x)$ & $\cos 510^{5}$ & PARTIC, (X) & \\
\hline $1 / 79$ & 34.263 .11 & 40,87 & $28,341,63$ & 33,80 & $7,647,30$ & 9,12 & $4,453,86$ & 6,31 & $0.120,49$ & 10,89 & $83.826,39$ \\
\hline $11 / 79$ & 45229,59 & 41,74 & $37,142,25$ & 34,28 & $9.851,65$ & 9.09 & $6.603,31$ & 5,17 & $10.512,88$ & 0.70 & $108.339,98$ \\
\hline $1 / 80$ & $69,492,91$ & 44,11 & $63,426,34$ & 33,01 & 13.867 .62 & 8,80 & $7.671,21$ & 4,87 & 13057.25 & 8,28 & $167.515,33$ \\
\hline $11 / 80$ & 97.058 .21 & 44,32 & 76.764 .42 & 34,69 & $19.266,08$ & 8,79 & $10.412,06$ & 4,75 & $16.481,81$ & 7,53 & $218.982,68$ \\
\hline $1 / 81$ & $132.003,91$ & 42,62 & $112.751,23$ & 36,40 & $28.045,05$ & 9,05 & $14,817,30$ & 4,78 & $22,096,07$ & 7,13 & $309.713,56$ \\
\hline
\end{tabular}

A Tabela A.5 foi construída a partir das tabelas A.3 e A.4. Supondose que as variações estimadas (Tabela A.4) no emprego total tenham recaído somente na faixa 1, alterou-se o n. de empregados por periodo que multiplica c salário médio da faixa no semestre. A metodologia foi a mesma da Tabela $A .3$ com esta única mudança para a faixa 1 . 
TABELA A.6:

COEFICIENTES DE REAJUSTE SEMESTRAL DO SALARIO MINIMO (INDICE PREÇO) E INDICE DA FOLHA DE PAGAMENTOS, EM TERMOS NOMINAIS E REAIS, SOB DUAS HIPOTESES ALTERNATIVAS (EMPREGO 79 CONSTANTE E VARIACCOES ESTIMADAS ABSORVIDAS NA FAIXA 1).

\begin{tabular}{|c|c|c|c|c|c|}
\hline \multirow[t]{2}{*}{ Perfodo } & \multirow[t]{2}{*}{$\begin{array}{l}\text { Indice de Preço } \\
\text { (Reajuste do Salário Minimo) }\end{array}$} & \multicolumn{2}{|c|}{$\begin{array}{c}\text { Folha de Pagamentos } \\
\text { (Hip6tese em P. Constante) }\end{array}$} & \multicolumn{2}{|c|}{$\begin{array}{l}\text { Folha de Pagamentos } \\
\text { (Hipótese Variação do Emp.) }\end{array}$} \\
\hline & & Indice nominal & Indice real & Indice nominal & Indice rea! \\
\hline $1 / 79$ & 100 & 100 & 100,0 & 100 & 100 \\
\hline $11 / 79$ & 129,3 & 129,3 & 100,0 & 129,24 & 99,95 \\
\hline $1 / 80$ & 182,83 & 183,60 & 100,42 & 187,90 & 102,77 \\
\hline $11 / 80$ & 255,04 & 258,18 & 101,23 & 261,23 & 102,42 \\
\hline $1 / 81$ & 372,88 & 382,01 & 102,44 & 369,47 & 99,08 \\
\hline $11 / 81$ & 525,38 & 545,43 & 103,81 & - & - \\
\hline $1 / 82$ & 731,34 & 770,10 & 105,29 & - & - \\
\hline
\end{tabular}

A Tabela A.6 apresenta o indice do MSMP, como um indicador de preços. Como os reajustes no salário mínimo excederam, nos primeiros semestres, as taxas do INPC, só passando a coincidir com elas nos últimos períodos, escolhemos como deflator mais apropriado os próprios reajustes do mínimo. Os índices nominais das folhas de pagamento foram calculados a partir das últimas colunas das tabelas A.3 e A.5. Esses índices nominais foram deflacionados pelos reajustes do MSMP, obtendo-se os índices reais das folhas de pagamento.

TABELA A.7:

EVOLUÇAO DO SALARIO MEDIO SOB DUAS HIPOTESES ALTERNATIVAS, EM CRUZEIROS CORRENTES E DEFLACIONADOS PELO COEFICIENTE DE REAJUSTE DO MSMP.

\begin{tabular}{|c|c|c|c|c|}
\hline \multirow[b]{2}{*}{ Perfodo } & \multicolumn{2}{|c|}{ Salário Médio em Cr\$ } & \multicolumn{2}{|c|}{ Indice de Salário Médio Real } \\
\hline & $\begin{array}{l}\text { Hipstese de emprego } \\
\text { constante }\end{array}$ & $\begin{array}{l}\text { Hip6teses de variaçōes } \\
\text { absorvidas pela faixa } 1\end{array}$ & Emp. Const. & $\begin{array}{c}\text { Variaçöes na } \\
\text { faixe } 1\end{array}$ \\
\hline $1 / 79$ & $6.247,70$ & $6.243,80$ & 100 & 100 \\
\hline $11 / 79$ & $8.080,32$ & $8.080,32$ & 100,02 & 100,08 \\
\hline $1 / 80$ & $11.474,56$ & $11.260,94$ & 100,41 & 98,6 \\
\hline $11 / 80$ & $16.136,29$ & $15.986,68$ & 101,2 & 100,3 \\
\hline $1 / 81$ & 23.876,06 & $24.490,13$ & 102,4 & 105,0 \\
\hline $11 / 81$ & $34.091,90$ & - & 103,7 & - \\
\hline $1 / 82$ & $48.135,00$ & - & 105,2 & - \\
\hline
\end{tabular}


A Tabela A.7 foi construída a partir das Tabelas A.3 e A.5. Os índices de deflacionamento usados foram os mesmos da Tabela A.6.

\section{REFERENCIAS BIBLIOGRAFICAS}

ARIDA, Pérsio (1981). "Reajuste Salarial e Inflação: Uma Sugestão de Política Econômica" in IX Encontro Nacional de Economia (ANPEC, Olinda, 8-11 dezembro de 1981, pps. 1485-1514).

BAUMGARTEN JR., Alfredo Luiz (1981). “A Aritmética Perversa da Política Salarial" in Revista Brasileira de Economia (Vol. 35, n. 4, out./ dez. 1981, pps. 317-337).

CAMARGO, José Márcio (1980). "A Nova Politica Salarial, Distribuição de Rendas e Inflação" in Pesquisa e Planejamento Econômico (Vol. 10, n⿳ㅇ 3, dezembro de 1980, pps. 971 -1000).

CARVALHO, Lívio (1981). "A Nova Política Salarial, Distribuição de Rendas e Inflação: Um Comentário" in Pesquisa e Planejamento Econômico (vol. II, n. 3, dezembro de 1981, pps. 803-817).

CARVALHO, Lívio (1982). "Políticas Salariais Brasileiras no Período 1964-1981" in Revista Brasileira de Economia (Vol. 36, n. I, Jan./ Mar. 1982, pps. 51-84).

KEYNES, John Maynard (1936). A Teoria Geral do Emprego do Juro e da Moeda. (Edit. Atlas, São Paulo, 1982).

KOUTSOYIANNIS, A. (1975). Modern Microeconomics (John, Wiley \& Sons, New York, 1975).

LARA RESENDE, André e LOPES, Francisco C. (1981). "Sobre as Causas da Recente Aceleração Inflacionária" in Pesquisa e Planejamento Econômicu (vol. II, n. 3, dezembro de 1981, pps. 599-616).

MACEDO, Roberto B.M. (1981). "Política Salarial e Inflação: A Experiência Brasileira Recente", (Instituto de Pesquisas Econômicas - USP, mimeog., São Paulo, 1981).

MORAES, Roberto C. (1982.a). “Os Efeitos Redistributivos da Inflação e os Reajustes Salariais" (IEPE-UFRGS, mimeog., Porto Alegre, 1982).

MORAES, Roberto C. (1982.b). "Inflação, Taxa de Lucro e Reajustes Salariais" in Ensaios FEE (Vol. 2, n. 2, 1982, Porto Aelgre).

SILVA, José Cláudio Ferreira da (1982.) "Apêndice: A Enganosa "Aritmética" do Salário Médio" in TAVARES, Maria da Conceição e DAVID, Maurício Dias (organizadores) A Economia Política da Crise (Ed. Vozes, Rio de Janeiro, 1982, pps. 81-87).

SOUZA, Janes Augusto de (1980). "Rotação de Pessoal na Construção Civil" in Conjuntura Econômica ('’ol. 34, n. 10, out. 80). 